\title{
Achieving robust acoustic emission-based damage characterization of scaled laminated composites under indentation
}

\author{
S. Fotouhi ${ }^{1 *}$, M. R. Khoshravan Azar ${ }^{1}$, M. Fotouhi ${ }^{2}$ \\ ${ }^{1}$ Faculty of Mechanical Engineering, University of Tabriz, 51666 Tabriz, Iran \\ ${ }^{2}$ School of Engineering, University of Glasgow, G12 8QQ Glasgow, UK
}

Received 3 January 2021; accepted in revised form 12 March 2021

\begin{abstract}
This paper presents a novel investigation on the robustness of Acoustic Emission (AE) technique on the characterization of indentation-induced Damage Mechanisms (DMs) in scaled laminated composites. AE is used to monitor a comprehensive series of scaled Quasi-Static Indentation (QSI) tests performed on Quasi-Isotropic (QI) S-glass/8552 epoxy composite plates, with in-plane and intra-plane scaling. A detailed assessment of the damage evolution is carried out through clustering of the monitored AE signals. The AE results indicated the existence of different DMs such as delamination, matrix cracking and fiber breakage. Ultrasonic C-scan and visual observations were also used to verify the AE based results. It was observed that both in-plane and intra-plane scaling alter the induced DMs, and the AE analysis was able to accurately identify and quantify the DMs in each case. However, the AE features (frequency, energy and count) were found to be dependent on different variables such as size, geometry and stacking sequence of the investigated samples. This research highlights the potential and challenges to develop AE as a reliable structural health monitoring system for impact/indentation damage monitoring of composite plates over a range of sizes and complexities.
\end{abstract}

Keywords: polymer composites, material testing, damage mechanism

\section{Introduction}

Nowadays, laminated composites have had an increasing usage in different industries such as aerospace, automotive and oil and gas. However, laminated composites are susceptible to impact-induced damage which is a main problem in their application. Impact damage caused by medium and high-velocity impacts is well detectable with a naked eye. Whereas low-velocity impacts (LVI) induced damage is invisible or barely visible, which is commonly called barely visible impact damage (BVID). Delamination, matrix cracking and fiber failure are the main induced Damage Mechanisms (DMs) in laminated composites (see Figure 1) when exposed to impacts. Delamination and matrix cracking are usually attributed to BVID due to the LVI and Quasi-Static Indentation (QSI) loadings [1-3].

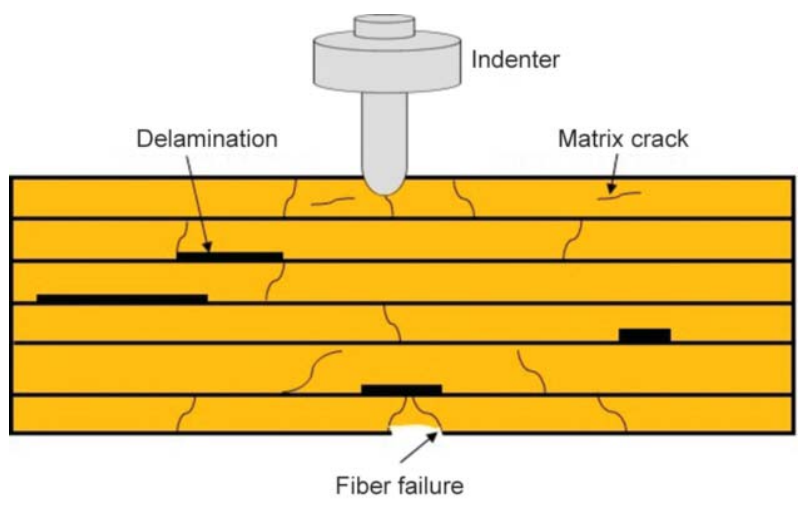

Figure 1. Main failure modes in fiber reinforced composite laminates under indentation and impact loadings. 
The existence of BVID leads to a decrease in laminated composite's compressive strength, which could eventually lead to catastrophic failure of the structure. Hence, understanding and characterizing BVID in laminated composites is of significant importance. Layup configuration, type of material, in-plane dimension, boundary condition, laminate thickness, and fiber direction are important parameters affecting the impact behavior and associated DMs of laminated composites [4, 5]. As laminated composites are used in structures of a variety of sizes, the extent/type of DMs in relation to the structure's size is investigated by extensive testing regimes. Full scale and large component testing of composite structures are expensive and challenging, therefore, there is a growing interest in the use of structural scale model testing, and applying the principles of dimensional scaling to evaluate the behavior of large scale structure [6]. Even though the relationship between underlying DMs in relation to the size effect in laminated composites is not well understood under impact loading [7], however, it is clearly reported that the DMs are changing due to the change in dimension. Figure 2 summarizes some relevant previous studies regarding the effect of dimension variations (ply thickness and laminate thickness) on the impact behavior of laminated composites. To highlight a few, Shen and Jiang [8] investigated the in-plane scaling effect (with same thicknesses) of unidirectional glass laminated composites under 6 different impact energies. The study indicated that scaling law can be used for elastic impact responses and showed that internal DMs such as matrix cracking and delamination exhibit dependence on the laminate's size. However, they do not suggest predicting the impact responses of large-scale laminated composites with very smallscale ones due to the microstructural effect when significant damage is generated [8]. Cantwell and Morton [9] studied the size effect on impact damage evolution in composite beams, and they concluded that increasing the length or thickness leads to a change in the type and location of the induced DMs. The damage was observed on the impacted side of the thick beam, while the thin beam experienced flexural failure on the non-impacted side. They also compared the impact test results on circular panels and beams, the conclusion was that the simple beam structures do not represent the DMs in more complex structures.

Ply-level and sublaminate-level scalings were mostly used for the intra-plane scaling of laminated composites under LVI/QSI [1, 3, 4, 10], as shown in Figure 3. It was found that due to the low energy release rate, thinner ply in the sublaminate sample had fewer

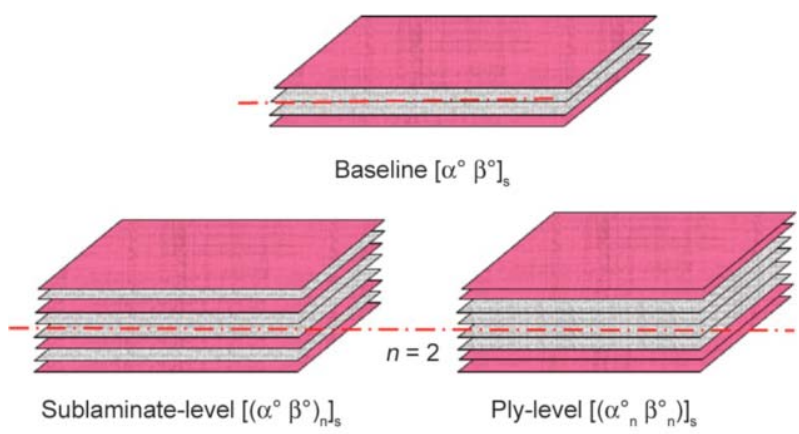

Figure 3. Schematic of the ply-level and sublaminate-level scaling techniques employed in the literature.

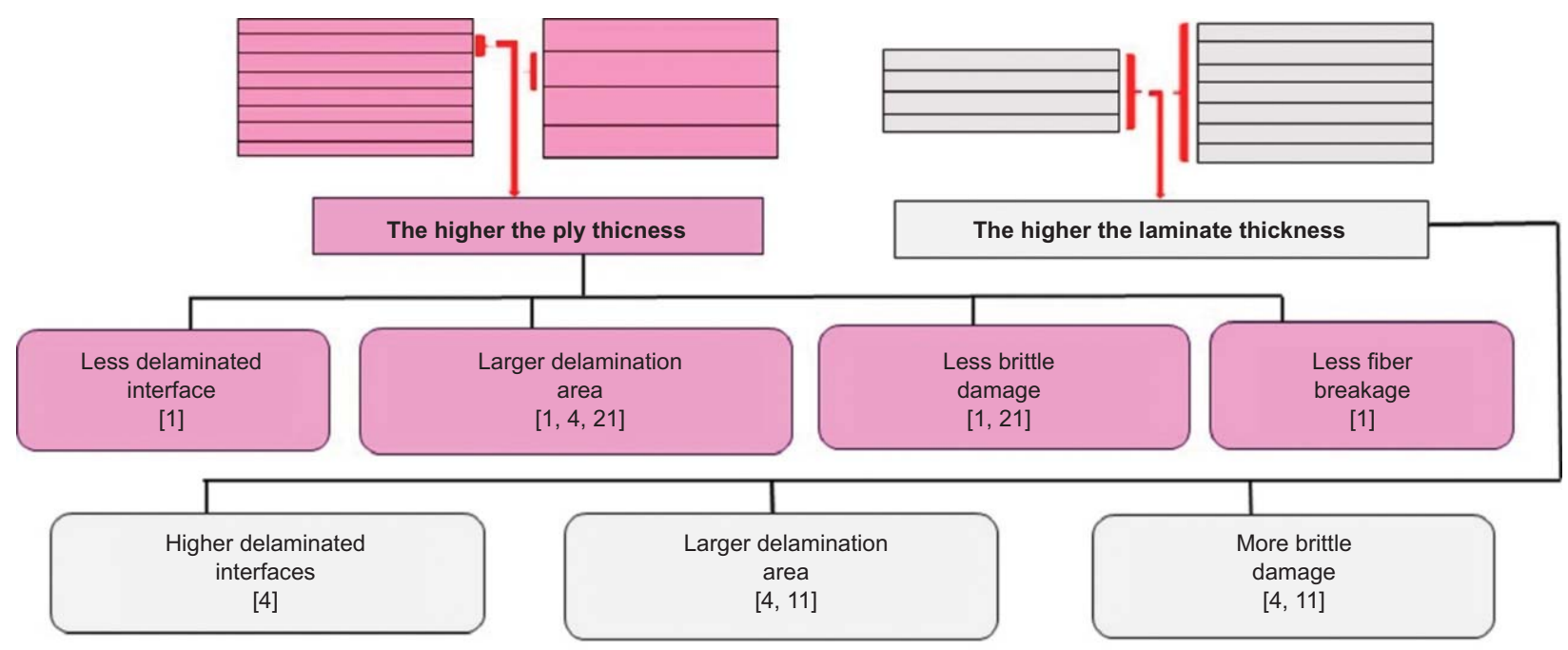

Figure 2. A summary of damage evolution by varying ply and laminate thicknesses in composites. 
microcracks and/or delamination, i.e. decreasing the ply thickness resulted in a lower matrix crack-induced delamination area [11].

A set of in-plane and intra-plane scaling effect on carbon/epoxy [10] and glass/epoxy [4] laminated composites under QSI were studied. The $\mathrm{C}$-scan and CT-scan results showed the thicker ply laminates lead to less resistance to matrix cracking before delamination. Besides, the matrix cracks' sizes depend on the ply thickness to in-plane dimension ratio. For the thick plates, local nonlinear behavior in the damaged area was considerably less than that for the thin plates. Comparing the overall DMs between the glass and carbon laminates, both laminates showed the same shape of delamination at respective interfaces with the presence of matrix cracks. The damage on the compression side of the glass laminates had no fiber failure, carbon laminates however, indicated compression side failure from the early stage of the loading just after the first load drop. Consequently, the analytical scaling laws were reported insufficient for predicting the DMs size, especially for the propagation stage, as it varied across different laminate configurations depending on the layup sequence and material properties.

To conclude, the literature review indicates the size and type of DMs under impact/indentation loadings significantly depend on the laminate and ply size, stacking sequence and material properties. Therefore, BVID damage prediction requires robust Non-Destructive Evaluation (NDE) techniques such as C-scan and CT-scan to evaluate the damage state to make maintenance and repair decisions. While NDE is of critical strategic importance, it represents an additional overhead for the end-user. The alternative to NDE is Structural Health Monitoring (SHM) which offers the ability to monitor structures in real-time. SHM technology helps to significantly reduce the maintenance and repair costs besides boosting safety.

Acoustic emission (AE) is an SHM technique that provides passive monitoring and has a great potential for the identification of DMs in laminated composites under different loadings [12-16]. Sudden strain energy release is caused by the occurrence of different DMs such as BVID in laminated composites can generate AE signals [3]. AE has been used for BVID detection in IM7-carbon/epoxy laminated composites $[1,3]$. However, significant work is required to evaluate the efficiency of AE in monitoring BVID in scaled laminated composites and layup variations.
This paper aims to address such a gap in the literature by carrying out an AE-based comprehensive experimental study to identify the damage evolution on a series of scaled Quasi-Isotropic (QI) S-glass/8552 epoxy composite plates. The investigated plates were scaled with in-plane and intra-plane and were subjected to QSI tests. Laminated composites, under QSI and LVI tests, usually show similar damage evolution $[17,18]$. In addition, there are no distinct differences between the dent depth, back surface crack size and load-deflection behaviors of laminated composites under QSI and LVI tests. So, QSI is often used instead of LVI to ease the interruption at different indentation levels for damage investigation [19].

This study is of great importance and can pave the way towards industrial implementation of $\mathrm{AE}$ for BVID detection, as it is not yet clear if $\mathrm{AE}$ is reliable in complex structures or not. In addition, a better understanding of the DMs using AE can help in better design of these structures considering the size and other design requirements.

\section{Materials and test methods}

S-glass fiber/8552 epoxy unidirectional prepregs from Hexcel Corporation (UK) was used for manufacturing the samples. Table 1 shows the mechanical properties of the glass prepreg which was utilized for the samples. The laminates consisted of $\left[45_{\mathrm{m}} / \mathrm{m}_{\mathrm{m}}\right.$ $\left.190_{m} /-45_{m}\right] \mathrm{ns}$ layers. The variables $n$ and $m$ vary for applying different scaling as Figure 4 illustrates. One reference sample $(\mathrm{R})$ and three other different scaled samples are considered. The in-plane dimensions of the R samples are $50 \times 75 \mathrm{~mm}$. However, as shown in Figure 4, the remained 3 samples have in-plane dimensions of $100 \times 150 \mathrm{~mm}$ based on the ASTM standard [20]. The samples are named Ply Scaled, Sublaminate Scaled, and In-plane Scaled (with PS, SS, and IS symbols respectively). The PS sample is considered as a full-scaled sample for the R sample.

After manually laying the prepreg plies, the laminates were located on aluminum plates and were

Table 1. Material properties of the S-glass/epoxy prepreg (modulus is calculated using the rule of the mixture).

\begin{tabular}{|ll|c|}
\hline \multicolumn{2}{|c|}{ Material } & S-glass/epoxy \\
\hline Young modulus, $E_{11}$ & {$[\mathrm{GPa}]$} & 47.7 \\
\hline Area weight & {$\left[\mathrm{g} / \mathrm{m}^{3}\right]$} & 190 \\
\hline Cured ply thickness & {$[\mathrm{mm}]$} & 0.155 \\
\hline Strain to failure & {$[\%]$} & 3.87 \\
\hline
\end{tabular}




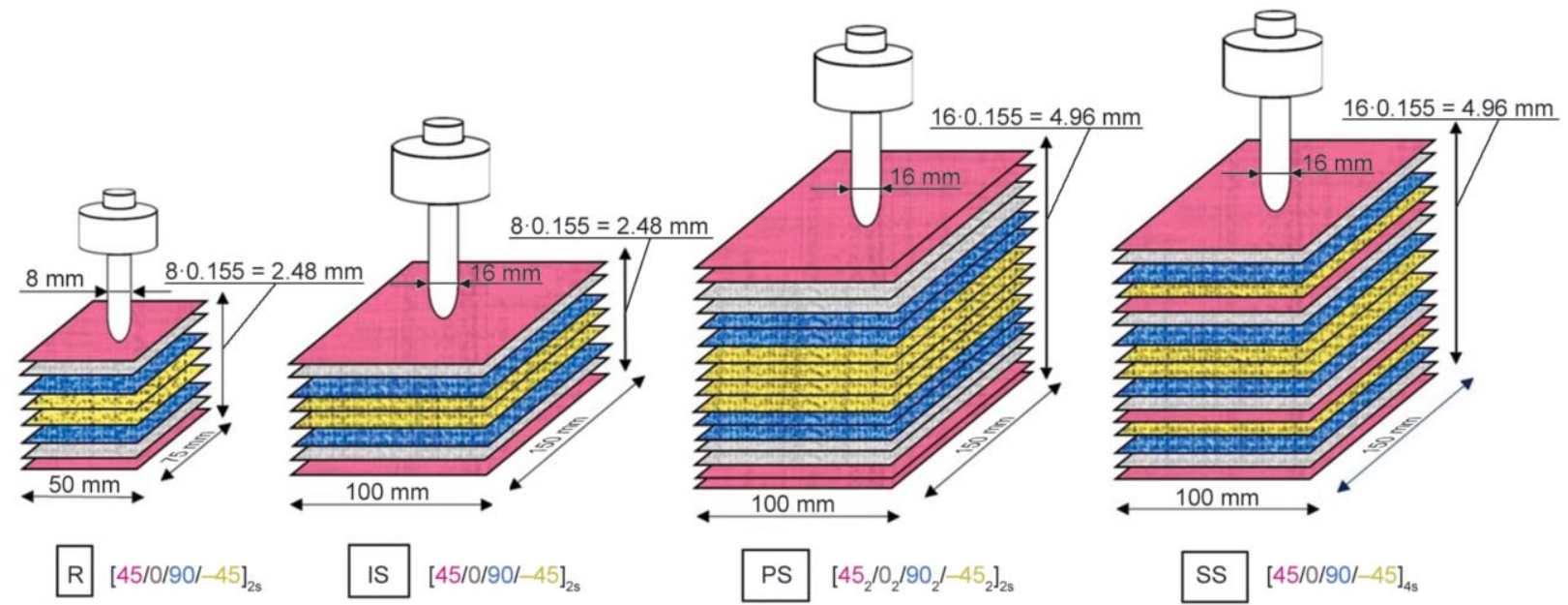

Figure 4. Schematic of tested laminated composite samples (dimensions are not scaled).

vacuum bagged at pressure of $0.1 \mathrm{MPa}$. Then they were put into the autoclave and cured at $110^{\circ} \mathrm{C}$ and followed by $180^{\circ} \mathrm{C}$ with the pressure of $0.69 \mathrm{MPa}$ (the recommended process for 8552 epoxy resin by Hexcel Corporation). After curing, the samples were subjected to indentation test based on the ASTM D7136/D7136M standard [20] (see Figure 5). A displacement rate of $1 \mathrm{~mm} / \mathrm{min}$ was applied using a hydraulic tensile machine (INSTRON 8872). The indenters, made of hardened steel, were attached to a $25 \mathrm{kN}$ load cell. The diameter of the indenters was $8 \mathrm{~mm}$ for the R sample and $16 \mathrm{~mm}$ for the rest of the samples. The samples were forced against a window by four clamps. The windows' sizes were $75 \mathrm{~mm} \times$ $125 \mathrm{~mm}$ for the PS, SS and IS samples and $62.5 \mathrm{~mm} \times$ $32.5 \mathrm{~mm}$ for the R sample. A software (Instron Wave Matrix Software Data) was used to record mechanical data from the load cell at a rate of $20 \mathrm{~Hz}$. As shown in Figure 5, four broadband Resonant-type (R15) and single-crystal piezoelectric sensors from Physical Acoustics Corporation (PAC), with optimal 20$900 \mathrm{kHz}$ frequency range, were placed on the impacted side of the samples to record AE data. Vacuumed silicon grease was used as the acoustical coupling. The AE data were acquired using the Mistras AE system (PAC) PCI-2. The rate and threshold of the signals' recording were $5 \mathrm{MHz}$ and $60 \mathrm{~dB}$ respectively. The recorded AE signals were enhanced by a 2/4/6-AST preamplifier. A pencil lead break procedure was used to calibrate the data acquisition system and ensure good conductivity between the specimen surface and the sensors [21].

For a better vision of the damage evolution, the experiments were stopped at 3 stages along with the
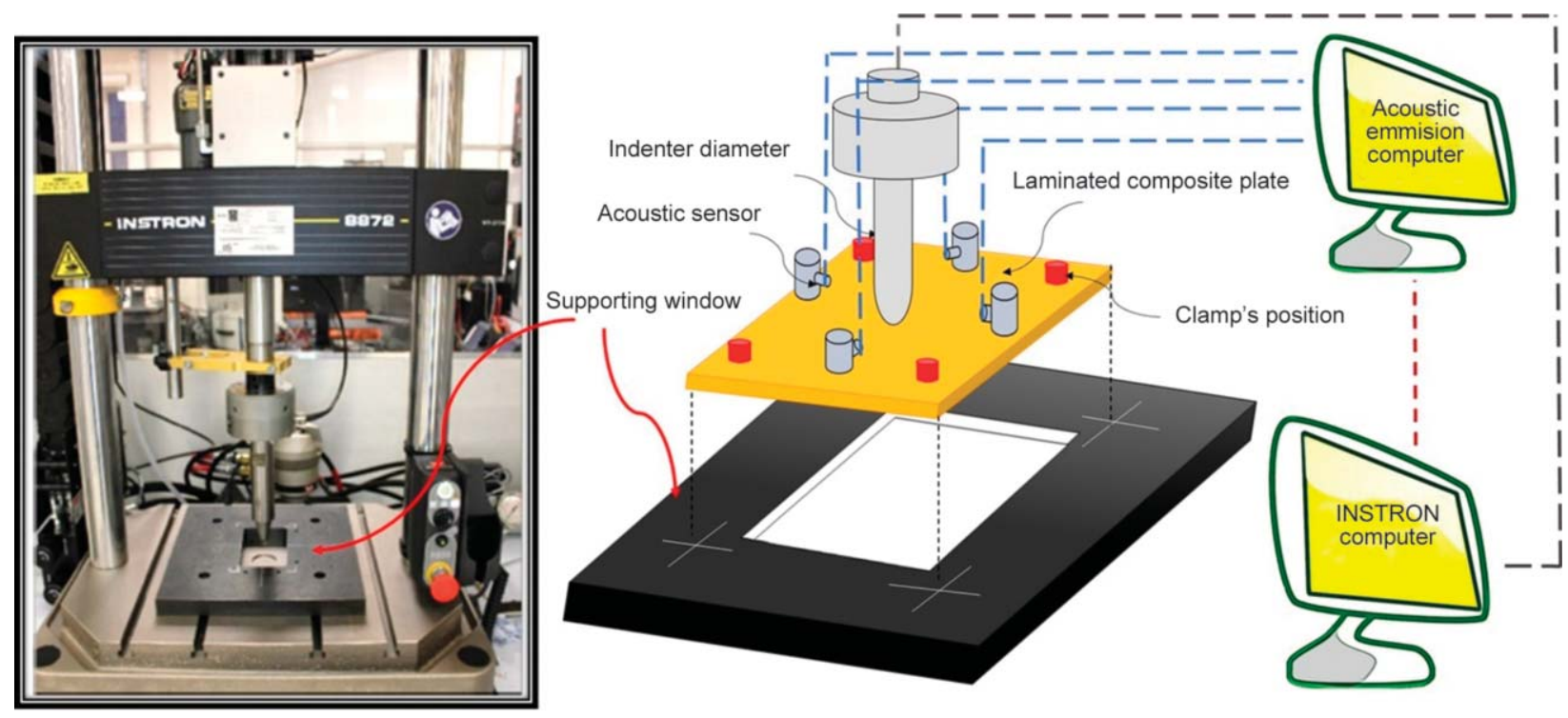

Figure 5. A view of the INSTRON machine and a schematic of the test setup. 


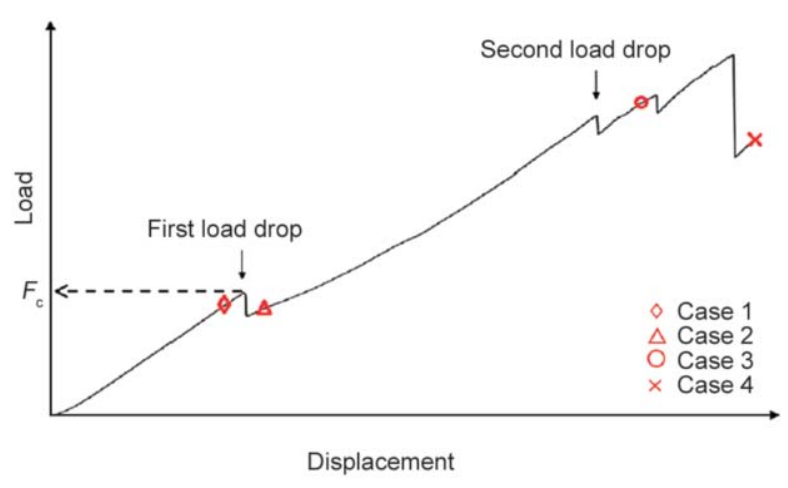

Figure 6. A typical overall graph for a QI laminated composite under QSI. The signs indicate the interruption points of the tests.

loading graph. Therefore, 3 cases were produced for each test case. Figure 6 shows a schematic load-displacement graph for the indentation tests with three different test scenarios as follows:

- Case 1: 1 sample was interrupted before significant fiber failure in the back face, to find the overall behavior of each case.

- Case 2: 1 sample was interrupted before the maximum load and after the second load drop.

- Case 3: 1 sample was interrupted immediately after the first load drop.

\section{Results and discussions}

\subsection{Mechanical behavior and AE results}

The load-displacement graphs for the investigated laminates under the QSI tests are shown in Figure 7.
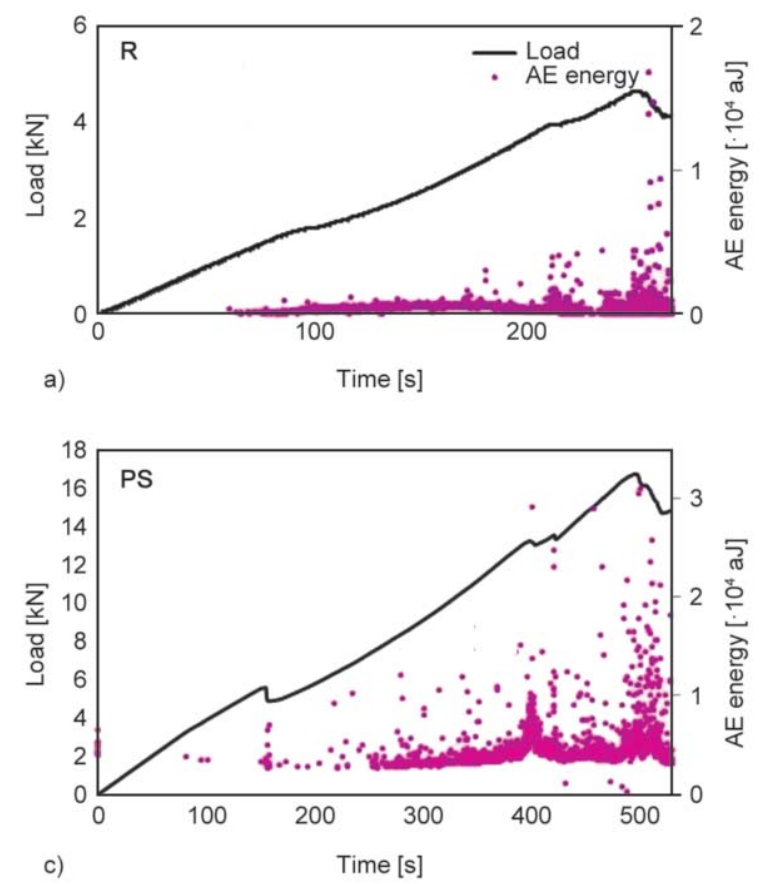

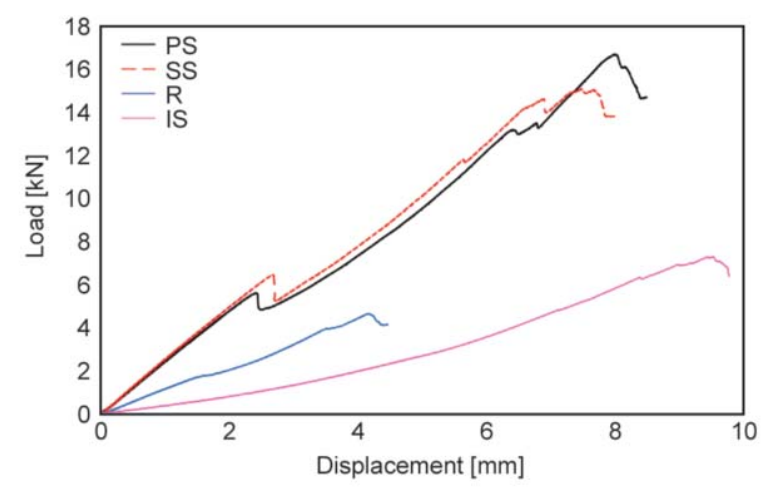

Figure 7. Load-displacement curves for the investigated samples just after the maximum load.

All four curves display similar global behavior. However, there are some dissimilarities in the stiffness, because of the thickness and in-plane sizes' variation of the samples. There is also a significant difference in the damage behavior of these laminates which is not easily noticeable from the load-displacement graphs. Figure 8 shows the load-time with simultaneous $\mathrm{AE}$ monitoring for the investigated laminates. Energy levels of the AE signals vary for different loading stages indicating the variation in the damage evolution due to the size and layup configuration difference. The first significant AE events for the SS and PS samples were seen near the first load drop with immediate signals. This large load drop was caused by delamination onset, which resulted in an immediate release of the stored energy that generates the AE signals with high energy content. There was no
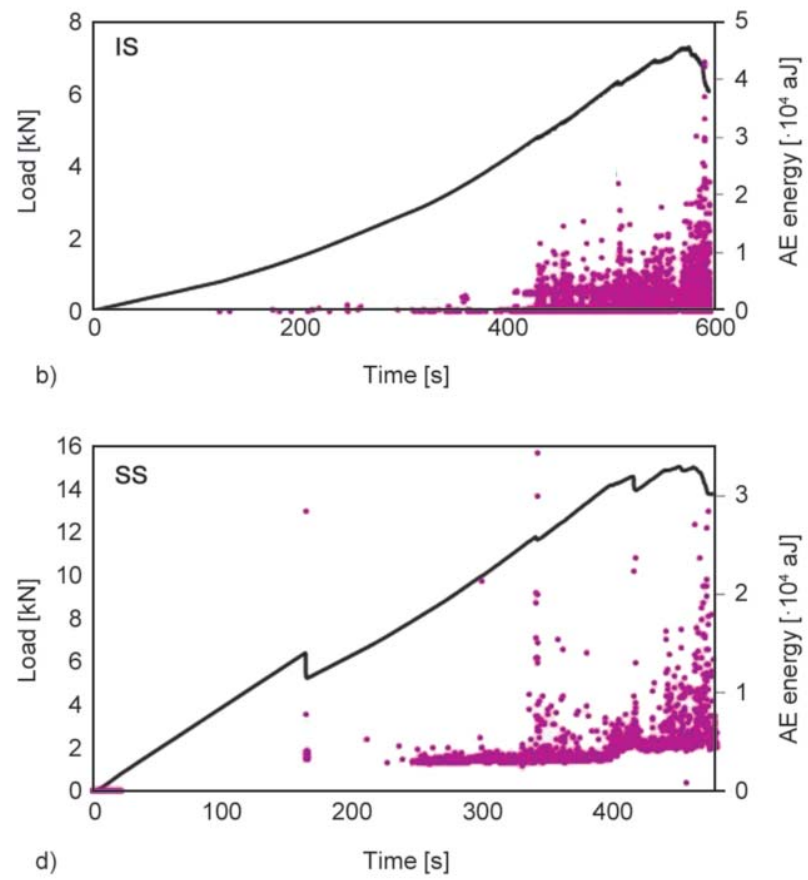

d)

Figure 8. Load-time and AE event energy distribution for the investigated samples. a) R, b) IS, c) PS and d) SS. 
considerable AE signals and no load-drop for the $\mathrm{R}$ and IS samples, showing a smooth initiation and growth of damage. In the following section, we aimed at characterizing the observed failure modes based on their resultant $\mathrm{AE}$ event features and correlating them to the observed DMs using $\mathrm{C}$-scan and visual observations.

\subsection{Clustering of the AE signals and their correlation with the DMs}

This section aims to characterize the DMs by multivariable clustering analysis of their AE features. Figure 9 shows a typical AE waveform and its schematic definition of different features of an AE signal. The monitored AE signals were generated from different DMs during the indentation tests. The AE signals have different features such as rise time, count, energy, duration, amplitude, and initial frequency. Initially, principal component analysis (PCA) is applied to these $6 \mathrm{AE}$ features to obtain lower-dimensional data while preserving as much of the data's variation as possible $[22,23]$. The percent of the total variability can be explained by each principal component (Figure 10). It can be seen from Figure 10 that the first two principal components, i.e. PCA (1) and PCA (2), contribute to above $70 \%$ of the total variability in the signals space for all the samples. This means that the first two PCA components have a 2D-projection that keeps more than $70 \%$ of the variance of the $6 \mathrm{AE}$-features, showing the capability of PCA to decrease the computational time and dimensions of the analysis.

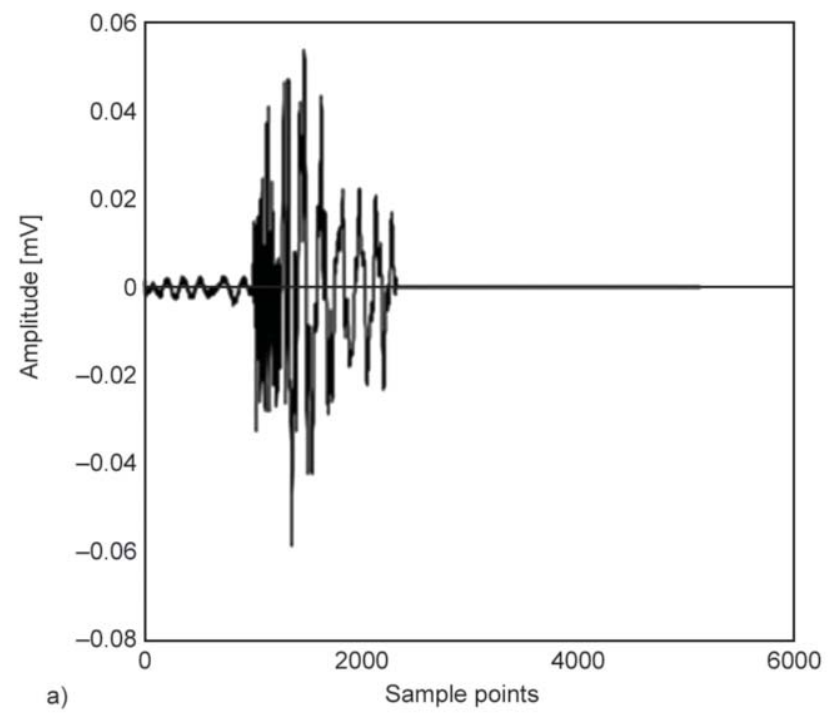

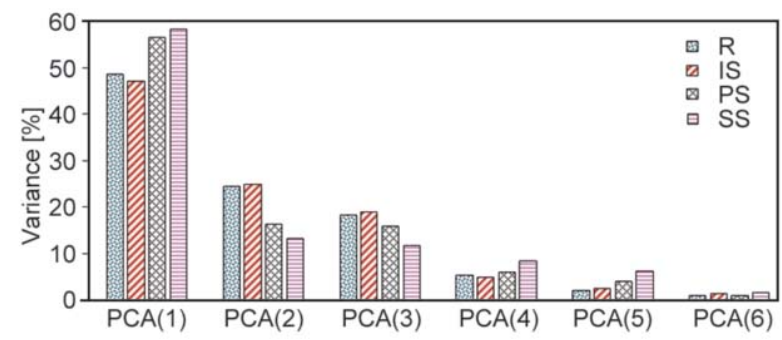

Figure 10. The variability percentage of each principal component for the investigated samples.

There are several commonly used clustering algorithms to classify AE signals including Gaussian Mixture Model (GMM) [24], Self-Organizing Map (SOM) [25], Fuzzy C-Means (FCM) [22], and Hierarchical Model (HM) [2]. For all these clustering methods, number of clusters needs to be defined. For this study, the optimum number of clusters was evaluated using Gaussian mixture distribution algorithm and Gap criteria, where the maximum value of Gap criterion shows the optimum solution. The Gap index shown in Figure 11, has the maximum value when the number of clusters is 3 , proving the optimum number of clusters. This is in agreement with previously published articles $[1,2,26]$ where 3 clusters were defined for the induced damage of laminated composites under LVI and QSI loadings. This also agrees with the $\mathrm{C}$-scan and visual observations of the investigated laminates where the dominant DMs are a combination of matrix cracking, delamination, and some fiber breakage as presented later.

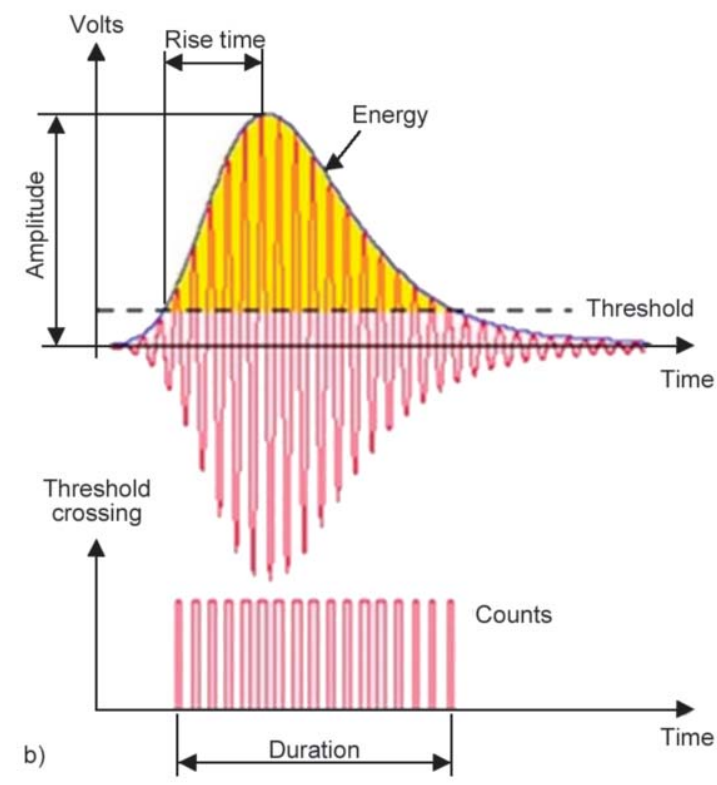

Figure 9. a) A typical AE waveform and b) the schematic definitions for AE features [23]. 


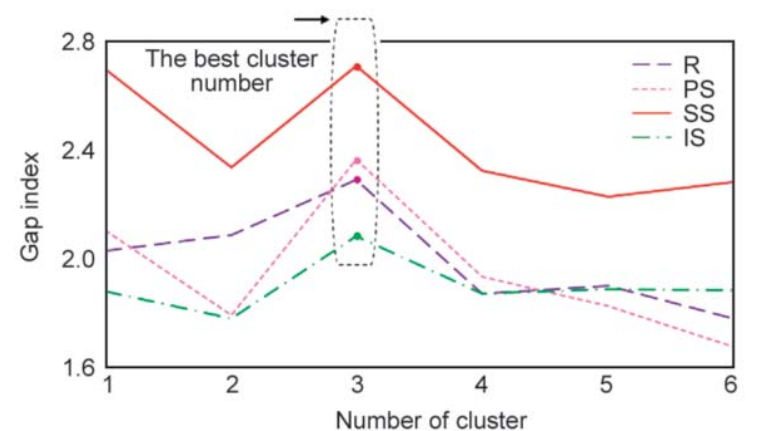

Figure 11. The optimum number of clusters for the AE signals using Gap criteria.

After identifying the number of clusters, the first two principal components were clustered in three different classes using the four clustering methods (FCM, SOM, GMM and HM). Figure 13 shows only the SOM clustering results, as this method showed the best distribution of the data with minimal overlap between the clusters. To correlate the three identified clusters to the observed DMs, the AE features belonging to each cluster were analyzed and the overall behaviors were compared with previous studies. Figure 13 illustrates the AE features distribution (frequency, count and energy) for the SOM clustered signals. Previous studies $[1,3]$ have shown that each DMs in indentation (matrix cracking, delamination, and fiber breakage) is associated with specific ranges of frequency. It was reported that the lower frequency

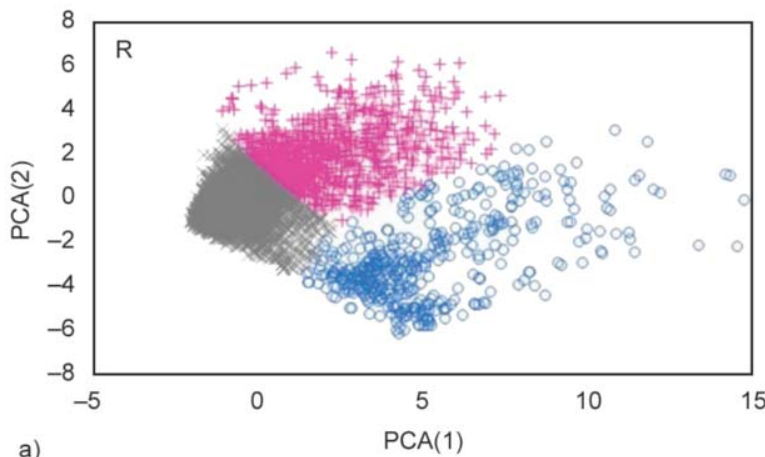

a)

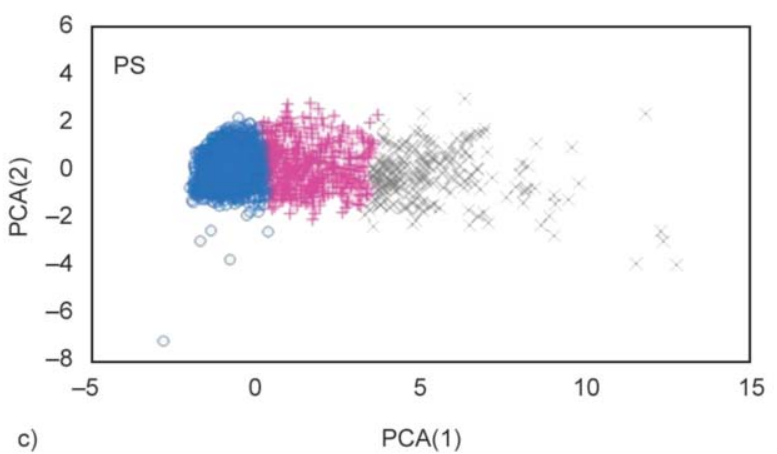

values are linked to matrix cracking, while the higher values are related to fiber breakage, and the frequency values in between are originated from delamination. This frequency difference relies on different visco-elastic relaxation processes for the DMs [27]. Considering the frequency distribution of the $\mathrm{AE}$ signals in Figure 13 the first, second and third clusters in Figure 12 represent the matrix cracking, delamination, and fiber breakage, respectively.

The frequency, energy and count ranges and percentages of each cluster for the investigated samples are categorized in Figures 14 to 16. For all the samples, the highest percentage of the AE signals is allocated to matrix cracking, the lowest percentage is associated with fiber breakage, and delamination has the middle range. This means that matrix cracking was the dominant DM, and there was not a considerable amount of fiber breakage. The percentage distributions of the AE signals associated with delamination and matrix cracking for the IS and SS samples are quite similar. A similar trend can also be observed for the PS and R samples. The fiber breakage associated with AE signals percentage has the highest value for the IS sample which can be due to a higher ratio of the in-plane dimension to the plate thickness [8].

Figure 14 shows that the frequency ranges of the DMs are varying considerably by the variation of the in-plane and intra-plane scaling, and layup sequence.
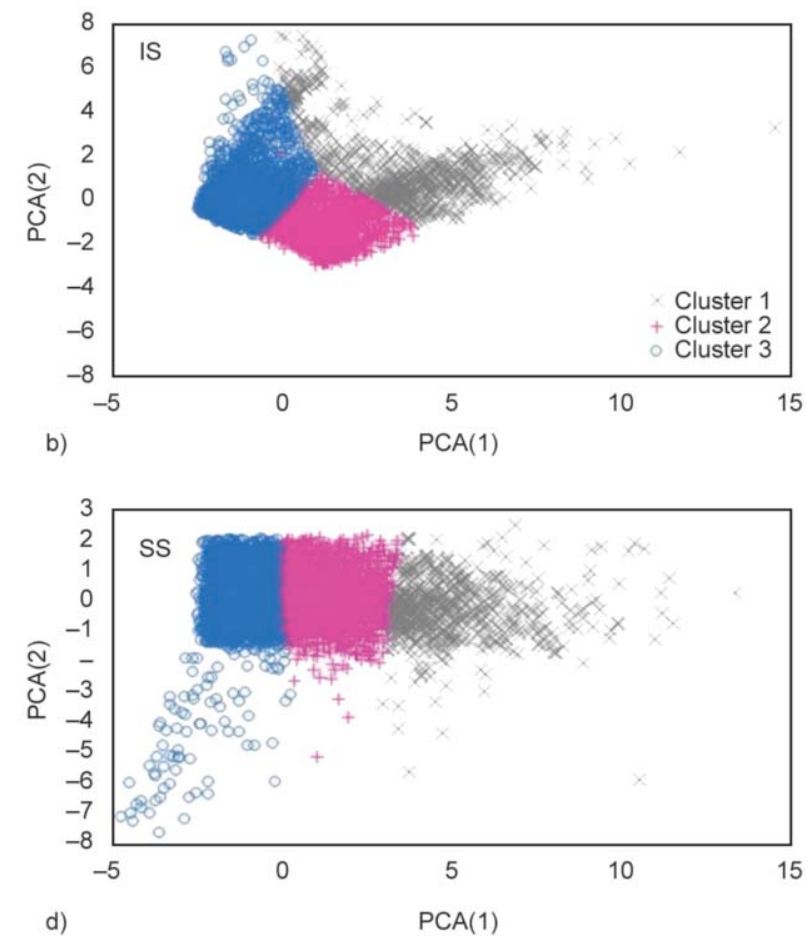

Figure 12. PCA visualization of the SOM clustering for the investigated samples. a) R, b) IS, c) PS and d) SS. 


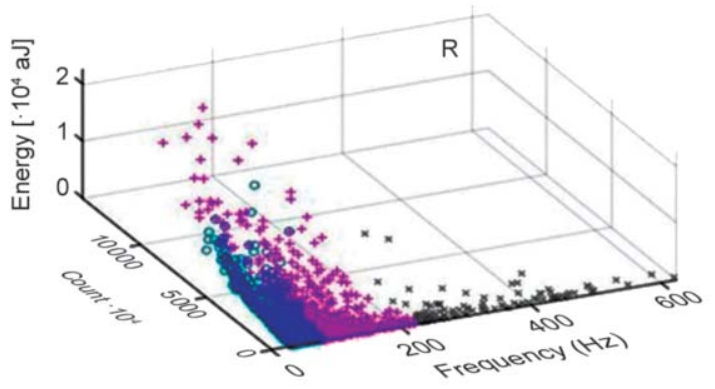

a)

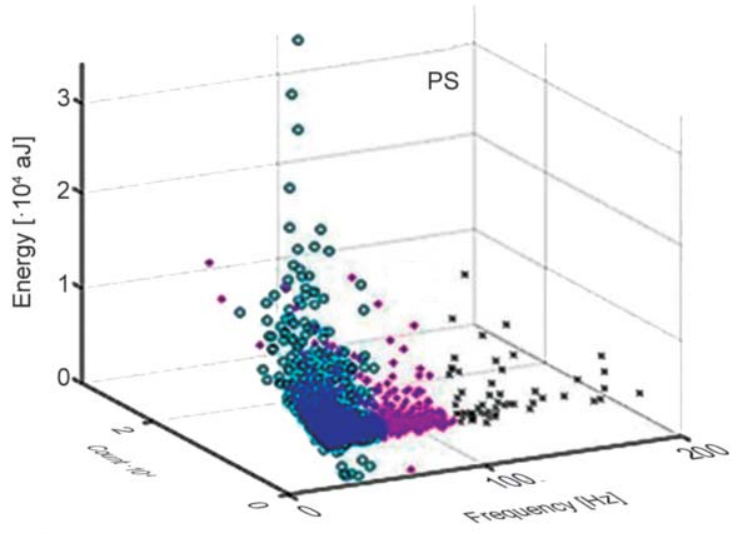

c)

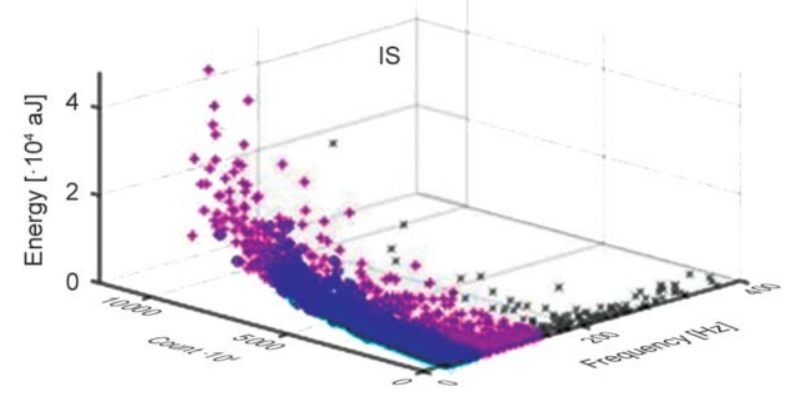

b)

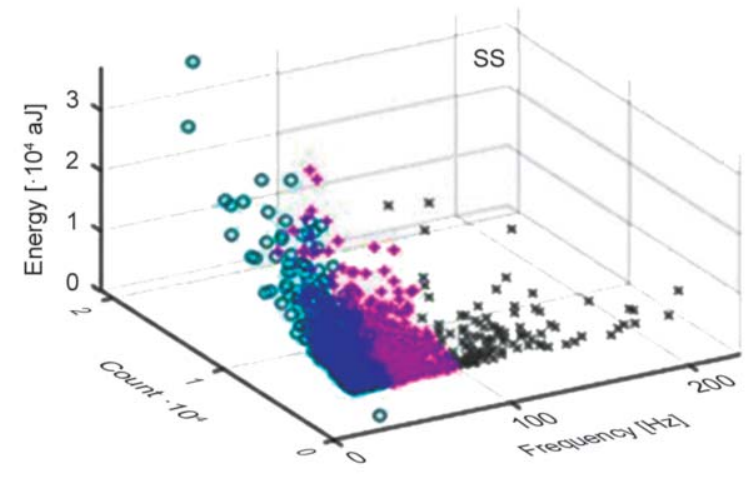

d)

Figure 13. SOM clustering of AE frequency, count and energy. a) R, b) IS, c) PS and d) SS.

The R sample has the smallest in-plane and thickness dimensions, and the fiber failure generated AE signals from the $\mathrm{R}$ sample have the highest frequency range (up to $625 \mathrm{kHz}$ ). While the PS sample has the largest ply thickness, and the fiber failure generates the lowest frequency range (up to $190 \mathrm{kHz}$ ). The fiber failure frequency range for the SS sample is slightly higher than the PS sample (up to $229 \mathrm{kHz}$ ). Whereas the IS sample, with the same in-plane dimension as SS and PS, and the half their laminate thickness, experienced a higher fiber failure frequency range (up to $384 \mathrm{kHz}$ ). A similar pattern can be seen for the delamination and matrix cracking damage. This reflects the dependency of the generated AE signals features on the laminate and plies dimensions. Increasing the laminate thickness, ply thickness and in-plane dimension decreases the frequency range generated by the associated DMs. The difference in the frequency distribution range is due to the different visco-elastic relaxation processes and associated relaxation times for the DMs $(f \sim 1 / \tau)$, where $f$ is frequency and $\tau$ is the relaxation time [27]. This highlights that the relaxation time for each DM in the larger samples (PS and SS) is higher than the small size samples (R and IS).
Unlike the frequency, the energy and count distributions in Figures 15 and 16 have significant overlap in different clusters. However, the energy and count distributions have their lowest range for the $\mathrm{R}$ sample. This results from the decrease in the size of the DMs (volume) for the R sample compared with the larger samples. The size scaling does not have a distinguishable pattern on the energy and count distributions when comparing the larger samples (PS, SS and IS). This is due to the complex nature of the DMs that generate AE signals with overlapping energy and count features. It is a common belief that high energy AE signals originate from fiber breakage [28]. However, Figure 15 shows that this statement may not correspond to reality, as delamination and matrix cracks can generate higher energy AE signals than fiber breakage. This argument agrees with some previously published works, concluding that the amplitude and energy are unreliable parameter in the damage monitoring using AE, as they are influenced by the pre-amplifier gain, the attenuation, and the propagation distance $[29,30]$.

Overall, increasing the laminate thickness significantly increases the energy and count features, while it decreases the frequency. It can therefore be concluded 
that despite a good clustering of the AE signals, the classification boundaries between the classes depend on the type of the investigated scaling variables. This is significant for real-life application of $\mathrm{AE}$, as the technique needs to consider these different variables

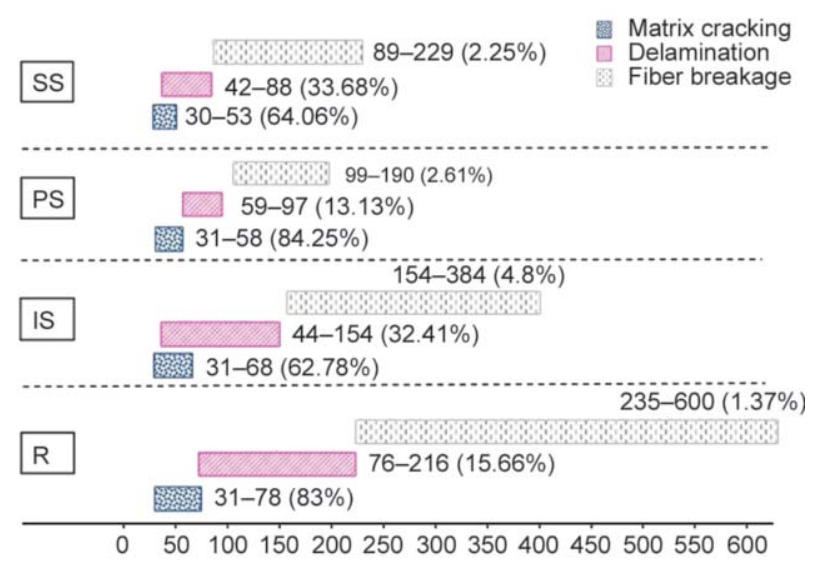

Figure 14. The attained frequency $[\mathrm{kHz}]$ ) range of the samples using the SOM clustering method.

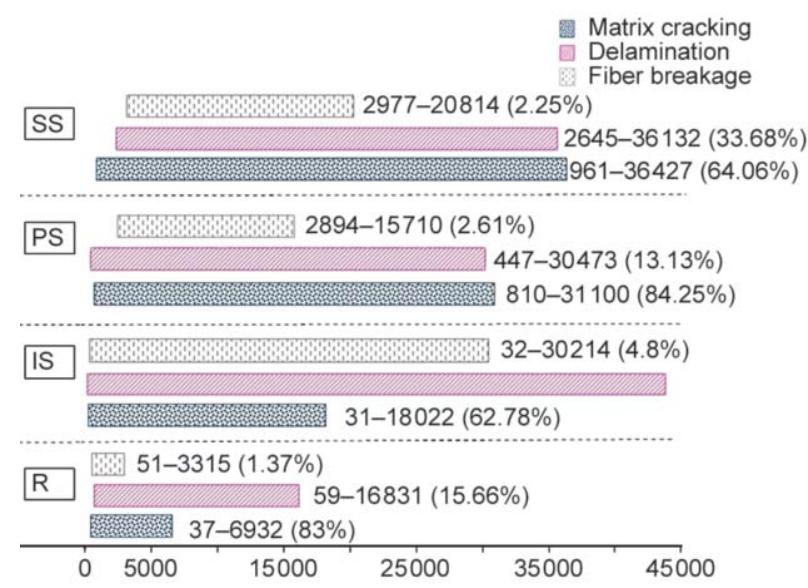

Figure 15. The attained energy range $[(\mathrm{aJ}]$ of the samples using the SOM clustering method.

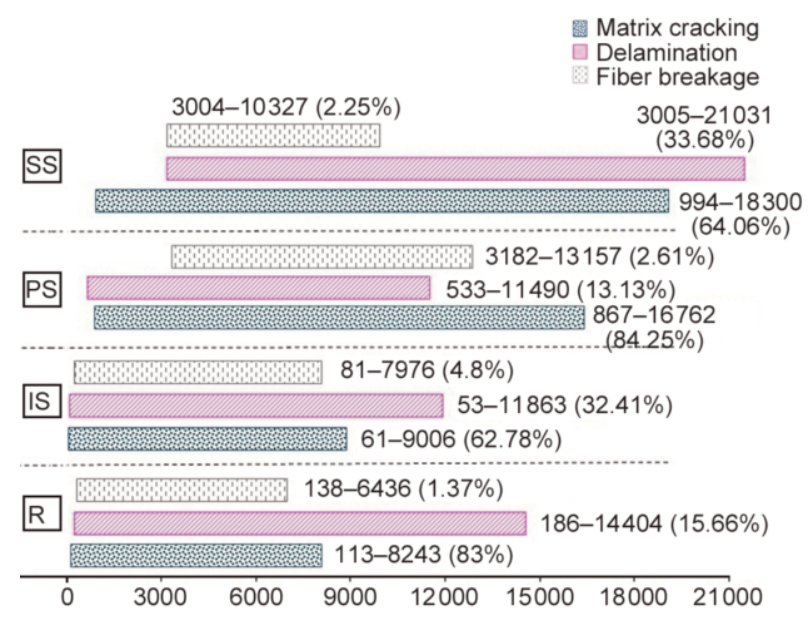

Figure 16. The attained count range of the samples using the SOM clustering method. to be able to effectively monitor different size, geometry and stacking sequence of laminated composites.

\subsection{Damage evolution and C-scan observations}

After identifying the clusters and their associated $\mathrm{AE}$ features, cumulative AE energy distribution is used to evaluate the damage evolution in the investigated samples as shown in Figure 17 and Figure 18. The lowest and highest values of the cumulative AE energy belong to fiber breakage and matrix cracking, respectively. This agrees with the dependency percentages of the AE signals reported in Figures 14, 15 and 16. No DMs were observed at the early stage of the loading process; however, some weak AE signals can be seen which might be related to some microscale damage and/or contact between the indenter and the sample.

For the PS and SS samples, the first significant AE signals and therefore significant rise in the cumulative AE energy diagram were detected near the first load drop, occurring long before the maximum load. The initial DM was matrix cracking which then followed by delamination and fiber failure. After the first load drop, the DMs propagate and there is an exponential cumulative AE energy distribution by increasing the load. For the IS and R samples, there was no visible load drop, however the slow rise of cumulative $\mathrm{AE}$ energies reflects the existence of the DMs starting more gradually. The visual inspection and $\mathrm{C}$-scans represented in Figure 17 show the damage existence at different loading stages, validating the AE observations.

The cumulative AE energy distribution for each DM in the samples with different sizes are presented in Figure 18 for the comparison purpose. Overall, the maximum cumulative AE energy associated with all the DMs are higher for the SS and PS samples compared with the other samples. This reflects the dependency of the AE energy content to the damage size, as SS and PS have significantly larger damage area compared to the $\mathrm{R}$ and IS samples (see the Cscan results in Figure 17). Further details can be seen regarding the sequence of the DMs in the samples. For example, it can be observed that the matrix cracking and fiber breakage are happening in the PS sample earlier than the other samples, which is due to the thicker ply thickness in this sample. 

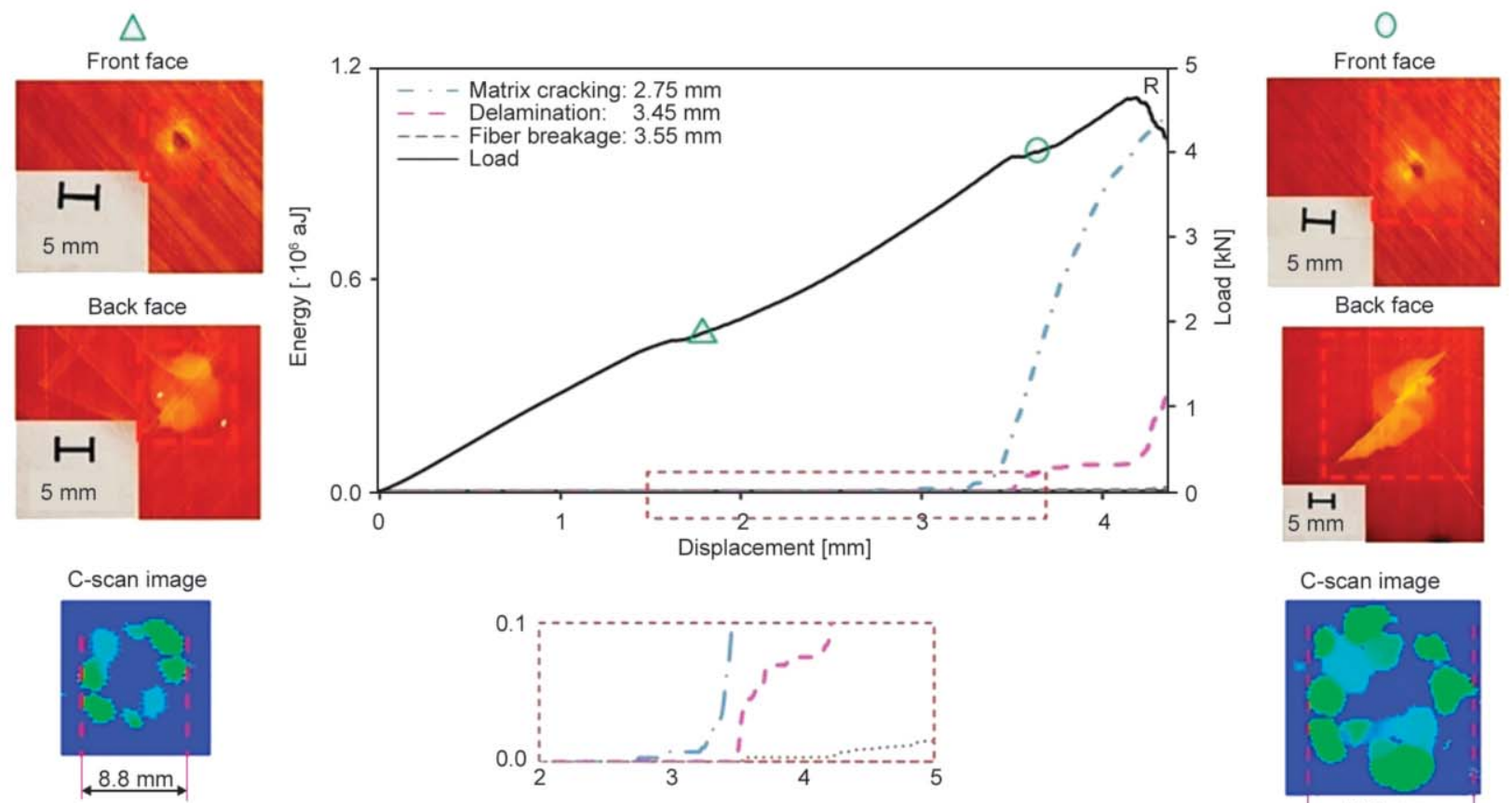

a)
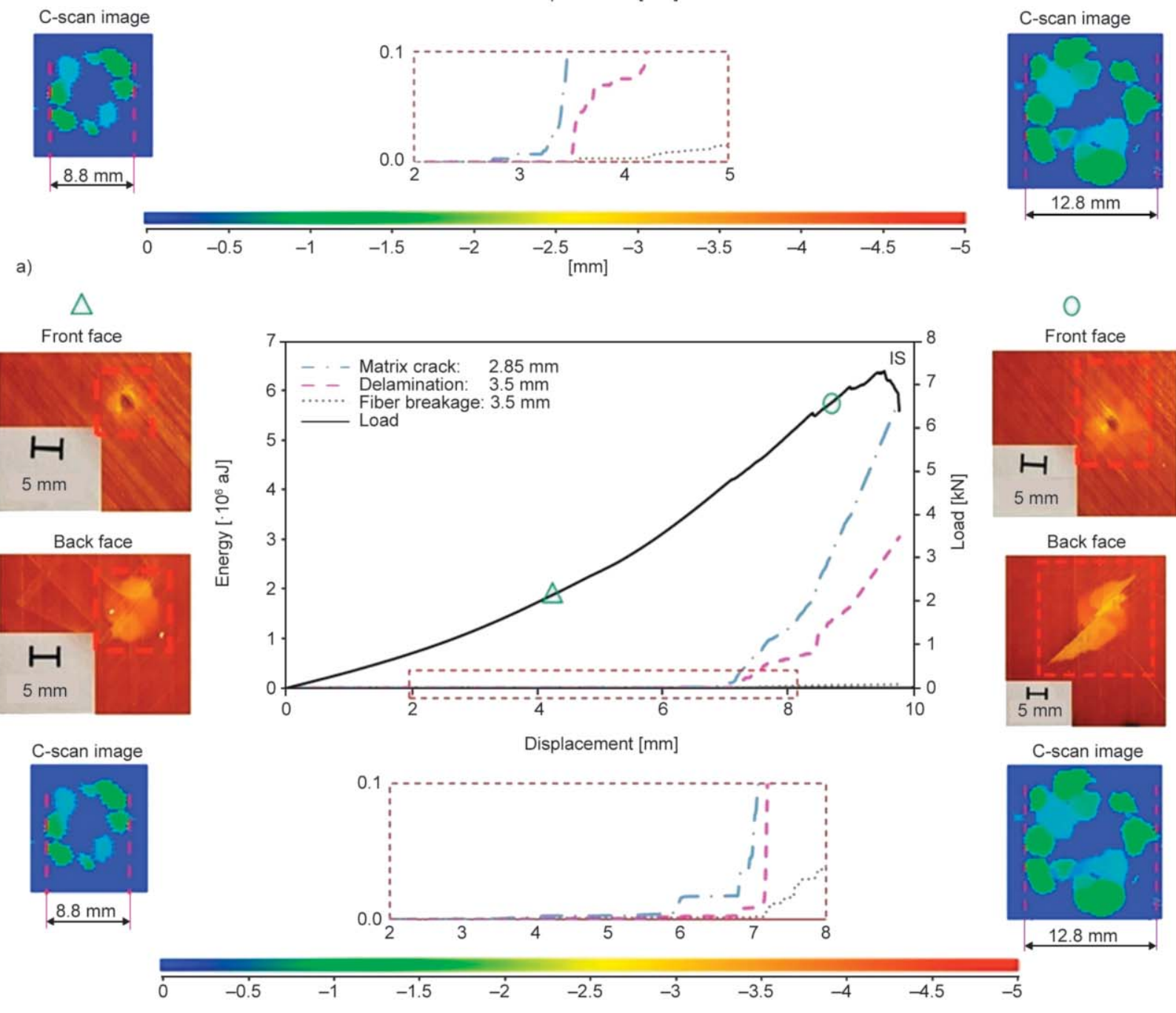

b)

$[\mathrm{mm}]$

Figure 17-1. C-scan and images taken from the samples, beside DMs' cumulative energies of the investigated samples. a) R and b) IS.

\section{Conclusions}

$\mathrm{AE}$ technique and multivariable clustering analysis were used to characterize the DMs generated in the QI S-glass/8552 epoxy laminated composites under QSI indentation tests, with in-plane and intra-plane scaling. The AE signals were clustered according to their $\mathrm{AE}$ features into three different classes by SOM. The clustered signals were then associated with their corresponding DMs (matrix cracking, delamination, and fiber breakage) considering their $\mathrm{AE}$ 


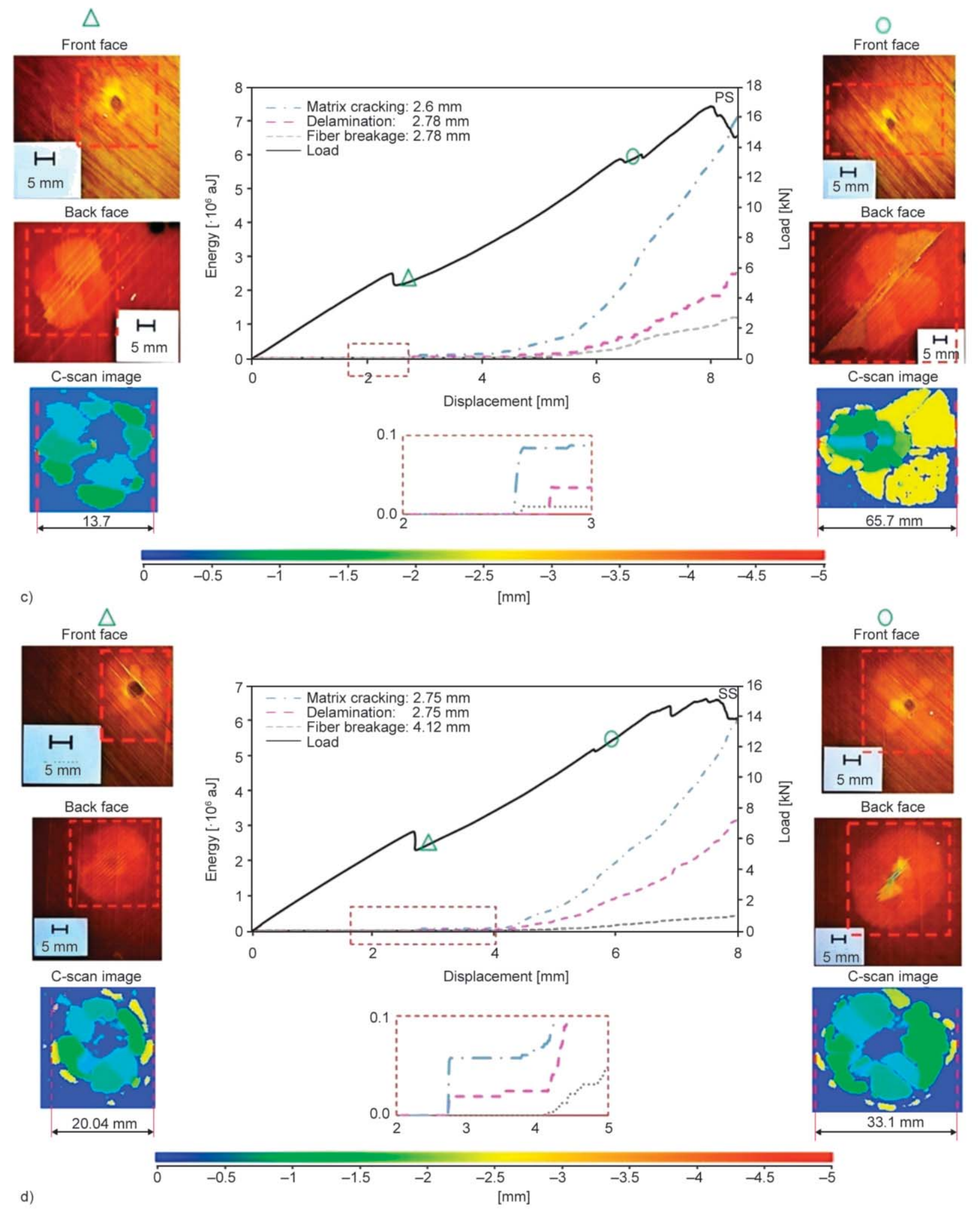

Figure 17-2. C-scan and images taken from the samples, beside DMs' cumulative energies of the investigated samples. c) PS and d) SS.

frequency range for each cluster. The lowest frequency range was associated with matrix cracking, fiber breakage had the highest frequency range, while the middle range frequency was associated with delamination. Matrix cracking, delamination and fiber breakage were found to be the most dominant DMs for all the investigated samples, respectively. Ultrasonic $\mathrm{C}$-scan and visual images show that similar DMs were observed for the scaled samples. The AE analysis was useful for data clustering and damage characterization, however increasing the laminate thickness, ply thickness and in-plane dimension decreases 

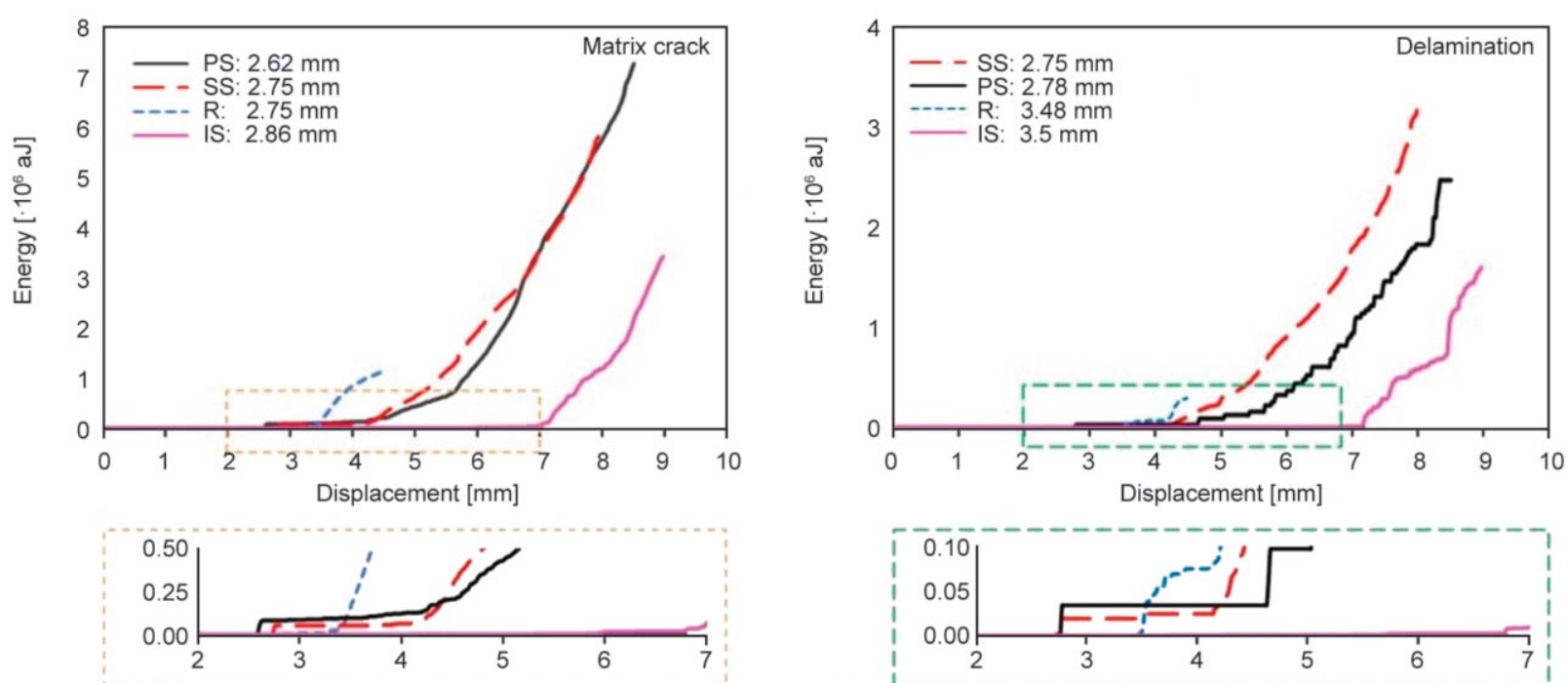

a)

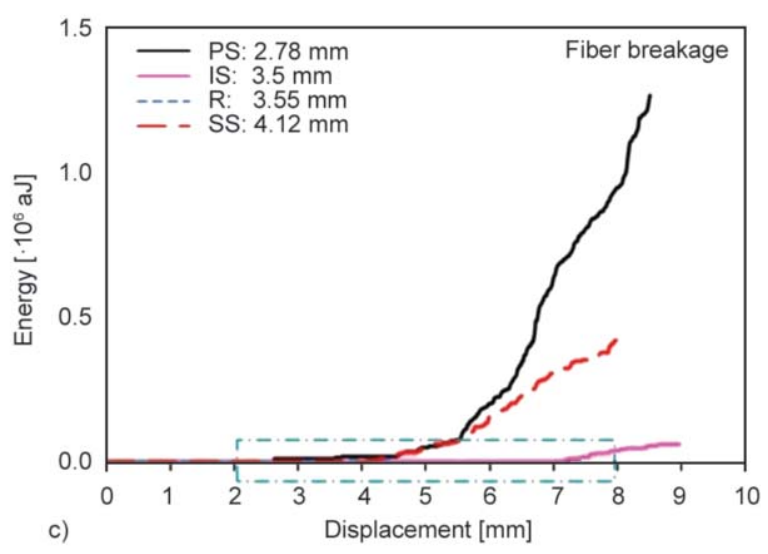

b)
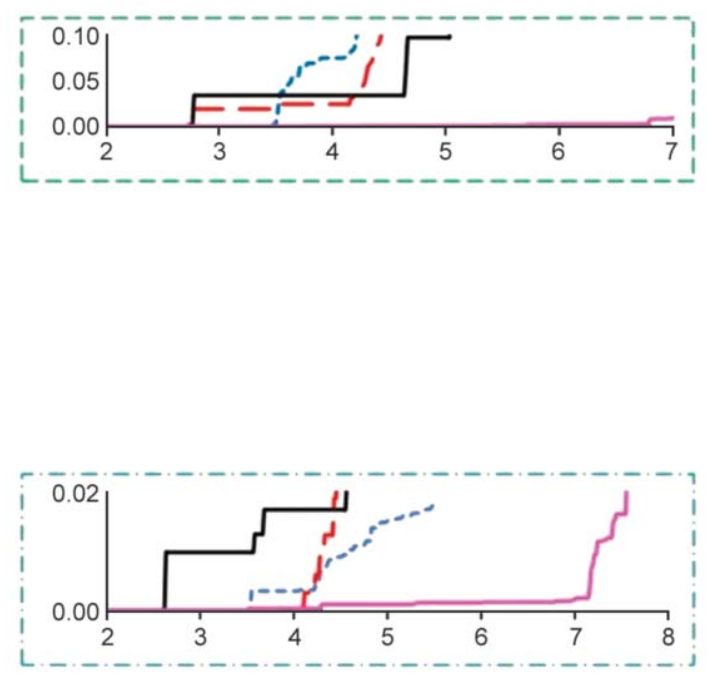

Figure 18. Comparing the scaling effect on cumulative AE energy for each DM (the related displacement at which each DM initiated is reported in the legends). a) Matrix cracking, b) delamination and c) fiber breakage.

the frequency range generated by the associated DMs. This highlights the sensitivity of the AE method for the in-plane and intra-plane scaling factors, reflecting the challenges in applying this method for monitoring different size laminated composites under indentation load.

\section{Acknowledgements}

Council (EPSRC) Programme Grant EP/V009451/1 on Next generation of high-performance impact resistant composites with visibility of damage.

\section{References}

[1] Saeedifar M., Najafabadi M. A., Zarouchas D., Toudeshky H. H., Jalalvand M.: Clustering of interlaminar and intralaminar damages in laminated composites under indentation loading using acoustic emission. Composites Part B: Engineering, 144, 206-219 (2018). https://doi.org/10.1016/j.compositesb.2018.02.028
[2] Saeedifar M., Zarouchas D.: Damage characterization of laminated composites using acoustic emission: A review. Composites Part B: Engineering, 195, 108039/1108039/21 (2020).

https://doi.org/10.1016/j.compositesb.2020.108039

[3] Saeedifar M., Najafabadi M. A., Zarouchas D., Toudeshky H. H., Jalalvand M.: Barely visible impact damage assessment in laminated composites using acoustic emission. Composites Part B: Engineering, 152, 180-192 (2018).

https://doi.org/10.1016/j.compositesb.2018.07.016

[4] Fotouhi M., Damghani M., Leong M. C., Fotouhi S., Jalalvand M., Wisnom M. R.: A comparative study on glass and carbon fibre reinforced laminated composites in scaled quasi-static indentation tests. Composite Structures, 245, 112327/1-112327/14 (2020).

https://doi.org/10.1016/j.compstruct.2020.112327

[5] Yang F. J., Cantwell W. J.: Impact damage initiation in composite materials. Composites Science and Technology, 70, 336-342 (2010).

https://doi.org/10.1016/j.compscitech.2009.11.004 
[6] Wagih A., Maimí P., Blanco N., González E. V.: Scaling effects of composite laminates under out-of-plane loading. Composites Part A: Applied Science and Manufacturing, 116, 1-12 (2019).

https://doi.org/10.1016/j.compositesa.2018.10.001

[7] Liu D., Raju B. B., Dang X.: Size effects on impact response of composite laminates. International Journal of Impact Engineering, 21, 837-854 (1998). https://doi.org/10.1016/S0734-743X(98)00036-0

[8] Shen Y., Jiang B., Li Y.: Scale effect on impact performance of unidirectional glass fiber reinforced epoxy composite laminates. Materials, 12, 1319/1-1319/14 (2019). https://oi.org/10.3390/ma12081319

[9] Cantwell W. J., Morton J.: Geometrical effects in the low velocity impact response of CFRP. Composite Structures, 12, 39-59 (1989).

https://doi.org/10.1016/0263-8223(89)90043-3

[10] Abisset E., Daghia F., Sun X. C., Wisnom M. R., Hallett S. R.: Interaction of inter- and intralaminar damage in scaled quasi-static indentation tests: Part 1 - Experiments. Composite Structures, 136, 712-726 (2016). https://doi.org/10.1016/j.compstruct.2015.09.061

[11] Ali H. T., Fotouhi S., Akrami R., Pashmforoushd F., Pavlovic A., Fotouhi M.: Effect of ply thickness on damage mechanisms of composite laminates under repeated loading. FME Transactions, 48, 287-293 (2020). https://doi.org/10.5937/fme2002287T

[12] Saeedifar M., Fotouhi M., Najafabadi M. A., Toudeshky H. H., Minak G.: Prediction of quasi-static delamination onset and growth in laminated composites by acoustic emission. Composites Part B: Engineering, 85, 113-122 (2016). https://doi.org/10.1016/j.compositesb.2015.09.037

[13] Mohammadi R., Saeedifar M., Toudeshky H. H., Najafabadi M. A., Fotouhi M.: Prediction of delamination growth in carbon/epoxy composites using a novel acoustic emission-based approach. Journal of Reinforced Plastics and Composites, 34, 868-878 (2015). https://doi.org/10.1177/0731684415583166

[14] Fallahi N., Nardoni G., Hossein H., Palazzetti R., Yan X. T., Zucchelli A.: Supervised and non-supervised AE data classification of nanomodified CFRP during DCB tests. FME Transactions, 44, 415-421 (2016). https://doi.org/10.5937/fmet1604415F

[15] Zarouchas D., van Hemelrijck D.: Mechanical characterization and damage assessment of thick adhesives for wind turbine blades using acoustic emission and digital image correlation techniques. Journal of Adhesion Science and Technology, 28, 1500-1516 (2014). https://doi.org/10.1080/01694243.2012.698122

[16] Loutas T., Eleftheroglou N., Zarouchas D.: A data-driven probabilistic framework towards the in-situ prognostics of fatigue life of composites based on acoustic emission data. Composite Structures, 161, 522-529 (2017). https://doi.org/10.1016/j.compstruct.2016.10.109
[17] Richardson M. O. W., Wisheart M. J.: Review of lowvelocity impact properties of composite materials. Composites Part A: Applied Science and Manufacturing, 27, 1123-1131 (1996). https://doi.org/10.1016/1359-835X(96)00074-7

[18] Aoki Y., Suemasu H., Ishikawa T.: Damage propagation in CFRP laminates subjected to low velocity impact and static indentation. Advanced Composite Materials, 16, 45-61 (2007).

https://doi.org/10.1163/156855107779755318

[19] Kaczmarek H., Maison S.: Comparative ultrasonic analysis of damage in CFRP under static indentation and lowvelocity impact. Composites Science and Technology, 51, 11-26 (1994). https://doi.org/10.1016/0266-3538(94)90152-X

[20] ASTM D7136/D7136M: Standard test method for measuring the damage resistance of a fiber-reinforced polymer matrix composite to a drop-weight impact event (2021).

[21] ASTM E976-15: Standard guide for determining the reproducibility of acoustic emission sensor response (2005).

[22] Fotouhi M., Sadeghi S., Jalalvand M., Ahmadi M.: Analysis of the damage mechanisms in mixed-mode delamination of laminated composites using acoustic emission data clustering. Journal of Thermoplastic Composite Materials, 30, 318-340 (2017). https://doi.org/10.1177/0892705715598362

[23] Huang M., Jiang L., Liaw P. K., Brooks C. R., Seeley R., Klarstrom D. L.: Using acoustic emission in fatigue and fracture materials research. JOM-e, 50, 1-12 (1998).

[24] Pashmforoush F., Fotouhi M., Ahmadi M.: Acoustic emission-based damage classification of glass/polyester composites using harmony search k-means algorithm. Journal of Reinforced Plastics and Composites, 31, 671680 (2012).

https://doi.org/10.1177/0731684412442257

[25] Oskouei A. R., Heidary H., Ahmadi M., Farajpur M.: Unsupervised acoustic emission data clustering for the analysis of damage mechanisms in glass/polyester composites. Materials and Design, 37, 416-422 (2012). https://doi.org/10.1016/j.matdes.2012.01.018

[26] Mahdian A., Yousefi J., Nazmdar M., Karimi N. Z., Ahmadi M., Minak G.: Damage evaluation of laminated composites under low-velocity impact tests using acoustic emission method. Journal of Composite Materials, 51, 479-490 (2017). https://doi.org/10.1177/0021998316648228

[27] Bohse J.: Acoustic emission characteristics of microfailure processes in polymer blends and composites. Composites Science and Technology, 60, 1213-1226 (2000). https://doi.org/10.1016/S0266-3538(00)00060-9 
[28] Fotouhi M., Suwarta P., Jalalvand M., Czel G., Wisnom M. R.: Detection of fibre fracture and ply fragmentation in thin-ply UD carbon/glass hybrid laminates using acoustic emission. Composites Part A: Applied Science and Manufacturing, 86, 66-76 (2016).

https://doi.org/10.1016/j.compositesa.2016.04.003

[29] Finkel P., Mitchell J. R., Carlos M. F.: Experimental study of 'auto sensor test-self test mode' for acoustic emission system performance verification. AIP Conference Proceedings, 509, 1995-2002 (2003).

https://doi.org/10.1063/1.1291316
[30] Oz F. E., Ersoy N., Lomov S. V.: Do high frequency acoustic emission events always represent fibre failure in CFRP laminates? Composites Part A: Applied Science and Manufacturing, 103, 230-235 (2017). https://doi.org/10.1016/j.compositesa.2017.10.013 